This is an electronic reprint of the original article. This reprint may differ from the original in pagination and typographic detail.

Author(s): Mukkala, Kirsi; Tervo, Hannu

Title: $\quad$ Air transportation and regional growth: which way does the causality run?

Year: $\quad 2013$

Version:

Please cite the original version:

Mukkala, K., \& Tervo, H. (2013). Air transportation and regional growth: which way does the causality run?. Environment and Planning A, 45(6), 1508-1520. https://doi.org/10.1068/a45298

All material supplied via JYX is protected by copyright and other intellectual property rights, and duplication or sale of all or part of any of the repository collections is not permitted, except that material may be duplicated by you for your research use or educational purposes in electronic or print form. You must obtain permission for any other use. Electronic or print copies may not be offered, whether for sale or otherwise to anyone who is not an authorised user. 


\section{Air transportation and regional growth: which way does the causality run?}

Kirsi Mukkala and Hannu Tervo

Jyväskylä University School of Business and Economics

P.O. Box 35, FI-40014 University of Jyväskylä

Finland

e-mails:

Kirsi Mukkala kirsi.mukkala@jyu.fi

Hannu Tervo (contact author) hannu.t.tervo@iyu.fi 


\title{
Air transportation and regional growth: which way does the causality run?
}

\begin{abstract}
While there is typically a strong correlation between air traffic and economic growth, the causation between the two is not clear. To address the existence of causality in this paper, we consider the nature of this relationship in different types of regions. The empirical analysis is based on European-level annual data from 86 regions and 13 countries on air traffic and regional economic performance in the period of 1991-2010. The Granger non-causality analysis in a panel framework that allows possible heterogeneity between regions is used. The results suggest that the causality processes are homogenous from regional growth to air traffic. There is causality from air traffic to regional growth in peripheral regions but the causality is less evident in core regions. Thus, air transportation plays a crucial role in boosting development in remote regions. There might be a case for subsidizing local airports in these regions.
\end{abstract}

Keywords: Air traffic; Accessibility; Regional growth; Peripheral regions; Granger noncausality; Panel data

\section{Introduction}

As economies continue to be affected by growing globalization, the role of airports has become increasingly important. Transportation in general, and air transportation in particular, is an important factor in realizing the economic potential of a region (Alkaabi and Debbage, 2007; Debbage and Delk, 2001; Goetz, 1992). However, providing transportation does not automatically lead to economic development. It may also work in reverse; economic development may spur a region to provide increased, better transportation. Thus, while there is typically a strong correlation between air traffic and economic growth, the causation between the two is not entirely clear (Button et al, 2010; Green, 2007; Ndoh and Caves, 1995). In a theory stressing the supply-side elements, the 
implementation of transportation infrastructure and accessibility leads to economic development, and airports act as catalysts for local investment. However, according to demand-side theory, economic development determines transportation needs and services. The question of whether demand-side or supply-side effects are more important remains largely unsettled.

Evaluating the character of the causal relationship between two variables can be problematic. Attempting to establish the core of causal processes is an issue that is central to the work of econometricians, and progress has been made toward answering the questions posed above. Earlier airport studies by Brueckner (2003) and Green (2007) utilized the methodology of instrumental variables (IV) in panel data to control for the potential endogeneity of airline traffic. The problem with the IV method is to find appropriate instruments that explain only airport activity, not regional growth.

Button et al. (1999) used Granger causality tests to conclude that airport traffic leads to economic development. These tests are designed to demonstrate causation by examining whether the lagged values of (say) one variable, $x$, carry explanatory power in the presence of the lagged values of a dependent variable, $y$ and possibly of other covariates, z. Granger causality testing exploits the fact that there is temporal ordering in a time series and assumes that effects cannot occur before causes. Conventional Granger causality tests, such as those in the 
study of Button et al. (1999), utilize time series data from only one observation. However, Granger tests are increasingly being used to evaluate causal relationships in panel data. Panel Granger tests are significantly more efficient than conventional Granger tests (Baltagi, 2005; Hood III et al, 2008; Hurlin and Venet, 2001; 2005), but a potential flaw shared by many analyses is an inappropriate assumption of causal homogeneity. In fact, the literature based on the early work of Hsiao (1986) and Holtz-Eakin et al. (1988) largely ignores the possibility of heterogeneity, in which a causal relationship may be present only in a subset of cross-sections but not in others. In our case, some airports may have a causal effect on economic development, while others do not, and vice versa.

In this paper, we consider the nature of the relationship between regional development and transportation infrastructure, as evidenced by air traffic. We ask whether accessibility is a key factor for economic success or its consequence. As this question is of the utmost importance to regional policy makers, we will analyze this causality in detail. Causality between regional performance and air traffic may vary according to the concept of peripherality because to grow, remote regions must be accessible via air connections. The development of core regions, on the other hand, is led by many agglomerative forces, and their success is not inevitably dependent on the impact of airports, although they naturally require efficient airlines. Within the framework of the New Economic 
Geography, the key question is whether reducing the transportation costs between core and peripheral regions allows the peripheral regions to capitalize on production cost advantages or whether economies of scale predominate (Krugman, 1991; Martin and Rogers, 1995). This theory suggests that there is an inverse U-shaped relationship between transportation costs and regional inequalities, with transportation cost reductions first increasing regional inequality and then reducing it. Improvements in transportation narrow output and wage differentials between the two types of regions only, if initial transportation costs are not too high (Venables and Gasiorek, 1998).

This paper aims to shed further light on the relationship between air traffic and economic performance in different types of regions, including remote regions serviced by small airports. We are especially interested in whether there are differences in the causal processes between core and peripheral regions. To test the relative importance of various effects, we will apply the Granger noncausality methodology in a panel framework. The empirical analysis herein is based on European-level annual data from 86 regions and 13 countries on air traffic and regional economic performance in the period of 1991-2010. To address the potential problem of heterogeneity, we employ the Hurlin and Venet (2001; 2005) procedure to identify the following three scenarios to describe the possible causal processes: homogeneous non-causality, homogeneous causality and heterogeneous non-causality. 
There are few prior studies of the economic impact of air transportation on regional development, and most of these have concentrated on large airports in core regions (an exception is, however, Button et al, 2010). A irport developments in peripheral regions are often approved on the basis that they will promote regional growth without there being any real empirical evidence to support that assertion. This paper aims to provide that evidence, making explicit its academic and policy impacts.

\section{The role of air transportation in regional growth}

It is generally assumed that as a region grows in population and national and international economic activity, air travel demand increases for that region accordingly (Goetz, 1992). However, it is also assumed that air transportation accessibility is one of several prerequisites for a region's increased growth and competitiveness. Air traffic provides a timely and reliable mechanism to transfer individuals, goods and services from one place to another in a globalized world. Quality airline service matters to firms because it facilitates face-to-face contacts with colleagues, suppliers, customers and other business collaborators. It supports the international competitiveness of firms and regions as a crucial part of a well-functioning transportation infrastructure. 
In peripheral regions, the competitive and locational advantages may be strongly influenced by airline networks because air traffic may weaken the negative effects of long distances. Improved accessibility allows firms in those regions to be more productive and more competitive than firms in regions with inferior accessibility. Improvements in the transportation infrastructure mean shorter travel times and better scheduling, thereby creating new locational advantages (Vickerman et al, 1999). Easy accessibility attracts firms and economic activity to a region and stimulates employment growth, even at established firms (Brueckner, 2003). Earlier studies and surveys clearly indicate that access to air transportation has an important effect on the locational decisions of many businesses (Debbage, 1999; Ivy et al, 1995; Ministry of Transport and Communication Finland, 2010). In particular, high-tech industries benefit from proximity to airports due to the importance of face-to-face interaction in their operations (Button and Taylor, 2000; Markusen et al, 1986). The debate over whether the accessibility of transportation secures general economic development or simply makes it possible continues (Debbage and Delk, 2001).

Debbage (1999) defined two ways in which the availability of air transportation affects the regional economy. First, the construction of an airport is a direct investment in the regional economy and generates on-site employment. The multiplier effects of such a large investment can be significant in sectors such as 
wholesale goods and ground transportation. Second, airline transportation can alter a region's economic links with other regions and create differences in regional competitiveness. The nature of the relationship between transportation infrastructure and regional development can be non-spatial or spatial. The former refers to the effects of infrastructure investment on the aggregate levels of economic activity, productivity and competitiveness in an economy. Spatial impacts, however, consider the role of infrastructure in differentiating performances in different locations, whether between regions or within regions. Accordingly, poor transportation infrastructure may limit the growth potential of the local economy (Peck, 1996; Vickerman, 1996).

The earlier literature focuses on the role of airports from the perspective of metropolitan development, whereas the relationship between airports and peripheral regions has been studied less thoroughly. Goetz (1992) found a positive relationship between air passenger flow volume and changes in population and employment growth. It remained unclear, however, whether the relationship is stronger for growth previous to increases in air passenger volume or subsequent to such increases. According to Green (2007), there is a causal relationship between airports and economic growth, but the direction of causality is not clear. Under a variety of specifications, however, Green (2007) found that passenger activity can predict growth. Brueckner (2003) focused on the link between airline traffic and employment in US metropolitan areas. The 
potential for reverse causality was accounted for by using instrument variables. The empirical findings confirmed the view that quality airline service is an important factor in urban economic development. Button et al. (1999) described the level of high-technology employment in US metropolitan areas using a number of positively related explanatory variables, including an airport dummy. In China, Yao and Yang (2008) found that airport development was positively related to economic growth, industrial structure, population density and openness but negatively related to ground transportation. They argued that the development of air transportation should be considered as an important stimulus to promote economic growth in remote provinces, reducing a country's overall spatial income and economic inequality. Button et al. (2010) used an econometric approach to analyze the role of small airports in economic development with panel data from the state of Virginia in the US. The results of this analysis varied depending on the manner in which the model was specified, but these authors concluded that local air transportation had a positive impact on regional per capita income.

\section{Implementation of the study}

In addressing the issue of causality, we evaluated the nature of the relationship between transportation infrastructure and economic development, but evaluating the character of a causal relationship between two variables is 
problematic. A standard tool used in econometrics is the Granger technique. In the case of two variables $x$ and $y$, the first variable, $x$, is said to cause the second variable, $y$, in the Granger sense if the forecast for $y$ improves when lagged values for $x$ are considered (Granger, 1969). By estimating an equation in which y is regressed on lagged values of $y$ and lagged values of $x$, we can evaluate the null hypothesis that $x$ does not Granger-cause $y$. If one or more of the lagged values of $\mathrm{x}$ is significant, we can reject the null hypothesis that $\mathrm{x}$ does not Granger-causey.

The introduction of a panel data dimension permits the use of both crosssectional and time series information to test causality relationships and apparently improves the efficiency of Granger causality tests (Baltagi 2005; Erdil and Yetkiner 2009). Granger tests can generate significant results with shorter time periods as the number of observations increases. Following Hurlin and Venet (2001; see also Erdil and Yetkiner, 2009; Hood III et al, 2008; Tervo, 2009), we consider the variables to be covariance stationary, observed for $T$ periods and $\mathrm{N}$ cross-section units (which consist of regions in our case). For each region $\mathrm{i} \in[1$, $\mathrm{N}$ ], the variable $\mathrm{x}_{\mathrm{i}, \mathrm{t}}$ causes $\mathrm{y}_{\mathrm{i}, \mathrm{t}}$ if we are better able to predict $\mathrm{y}_{\mathrm{i}, \mathrm{t}}$ when using all of the available information than when using only some of it.

Let us consider a time-stationary VAR representation adapted to a panel context. For each region $\mathrm{i}(\mathrm{i}=1, \ldots, \mathrm{N})$ and time period $\mathrm{t}(\mathrm{t}=1, \ldots, \mathrm{T})$ we have 
(1) $\quad y i, t=\sum_{k=1}^{p} \gamma^{(k)} y i, t-k+\sum_{k=1}^{p} \beta i^{(k)} x i, t-k+v i, t$,

where $v_{i, t}=a_{i}+\varepsilon_{i, t}$ are i.i.d. $\left(0, \sigma_{\varepsilon}{ }^{2}\right)$ and $p$ is the number of lags. The autoregressive coefficients $\gamma^{(\mathrm{k})}$ and the regression coefficient slopes $\beta_{i}{ }^{(\mathrm{k})}$ are assumed to be constant for all lag orders $k \in[1, p]$. It is also assumed that $\gamma^{(k)}$ are identical for all regions, whereas $\beta_{i}(k)$ are allowed to vary across individual regions. This is a panel data model with fixed coefficients.

Employing conventional Granger tests with panel data is not unproblematic. Indeed, problems may be caused by heterogeneity between the cross-section units. The first potential type of cross-section variation is due to distinctive intercepts. This variation is addressed with a fixed effects model in which heterogeneity is controlled by the introduction of individual effects $a_{\mathrm{i}}$. Another basis for heterogeneity is caused by the heterogeneous regression coefficients $\left.\beta_{i}{ }_{i} k\right)$; this is more problematic than the first situation and requires a more complex analytical response. If we consider model (1), the general definitions of causality imply testing for linear restrictions on these coefficients. The procedure has three main steps, which are related to the homogeneous non-causality, homogeneous causality and heterogeneous non-causality hypotheses (Figure 1). 


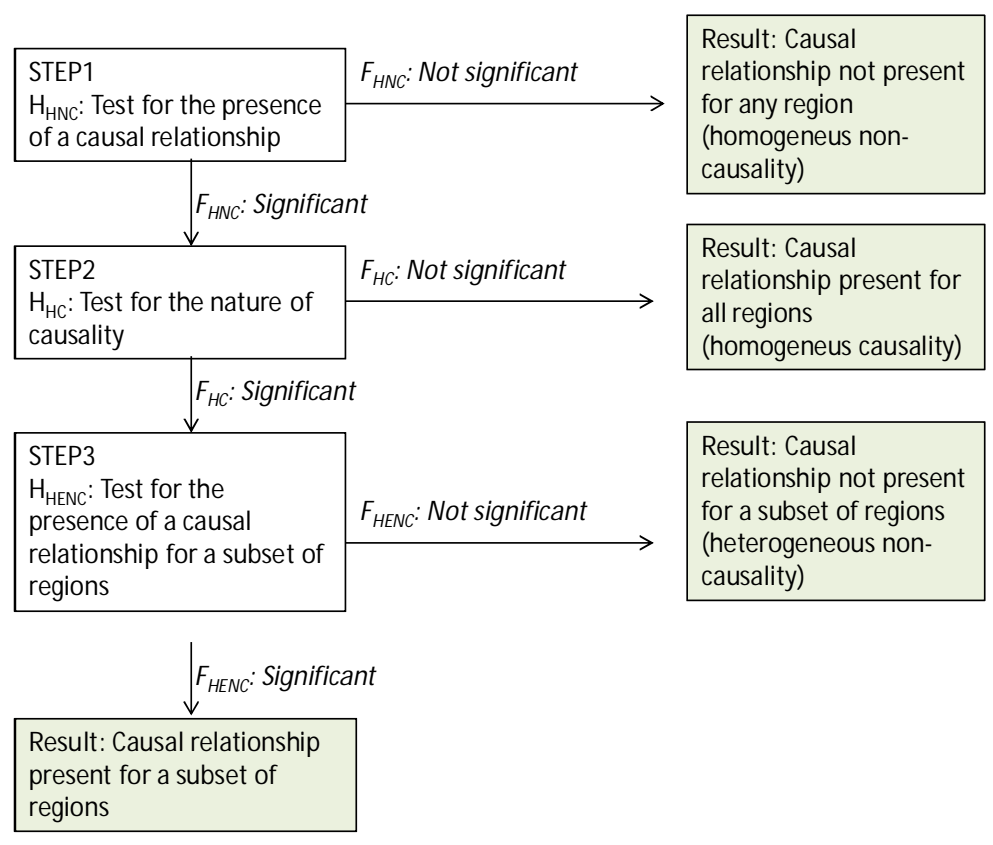

Figure 1. Testing procedure (cf. Hurlin and Venet, 2001)

The empirical analysis is based on regional-level data from Europe in the period of 1991-2010. ${ }^{1}$ The time period includes two global recessions and 9/ 11 which depressed demand for air travel. To perform a causal analysis between regional development and airport activity, we require two variables, for which we have different options. For the measurement of regional development, we use two variables, the first one measuring growth in employment and the second one measuring growth in purchasing power corrected real GDP. For the measurement of airport activity, we use a variable depicting development in the

1 Bak Basel Economics has produced the data set. 
number of commercial air passengers. An alternative variable depicts development in freight and mail cargo, but Green (2007) and Freestone (2009) have noted that this variable is imperfect. In addition, we use an accessibility variable. The accessibility concept is based on the idea of realizing an economic benefit out of easily reaching other regions and at the same time of being easily reached from other regions. The variable measures for each region a weighted average travel time to other European regions (the number of which is 291 in this data). The measure is multimodal, taking into account the best combination of air, rail and road travel. The weight used is the relative GDP or "market share" of each region. The variable is presented in index form. ${ }^{2}$

Airport Council International produces data on the use of airports in Europe, but these data are limited by the number of reporting airports, and the availability of airport data diminishes further as we go back in time. Because the availability of airport data is incomplete, the number of observations (regions) in the analysis is reduced remarkably. However, complete airport data are available for the period of 1991-2010 for 86 NUTS Level 2 or 3 regions from 13 countries in Europe (see A ppendix). ${ }^{3}$ This data set includes 3 regions from Austria, 3 from Switzerland, 13

\footnotetext{
2 For a more detailed description of the calculation of the total accessibility index, see Annex 1 in ESPON (2012).

3 The NUTS dassification (N omenclature of territorial units for statistics) is a hierarchical system for dividing up the economic territory of the EU for production of regional statistics and for socio-economic analyses of the regions. The NUTS nomenclature subdivides the economic territory of the European U nion into 97 regions at NUTS 1 level, 270 regions at NUTS 2 level and
} 
from Germany, 1 from Denmark, 22 from Spain, 12 from France, 2 from Ireland, 7 from Italy, 1 from Luxembourg, 2 from Holland, 2 from Norway, 3 from Portugal and 15 from the UK. The regions included in the data cover close to $40 \%$ of the total population and GDP produced in Europe. For the representativeness of the data, because the regions included in the data are distributed across Western Europe, we consider the data to represent this area. The data is not, however, from all European countries which may limit the representativeness of the results. To accomplish the panel causal tests, we have an adequate number of cross-section and time-series observations - in fact, the number of cross-section observations (regions) in relation to the length of the time-series cannot be too large from the point of view of the method.

To test the heterogeneous non-causality hypothesis in the third step of our testing procedure, we categorize the regions into three groups of equal sizes using the accessibility index (see Appendix). This methodology allows us to determine whether peripherality explains the differences in causal processes. Accessibility is lowest in peripheral regions, highest in core regions and midrange in intermediate regions. Table 1 shows that employment and real GDP are higher when the region is more accessible. The number of air passengers is also lowest in peripheral regions and highest in core regions.

1294 regions at NUTS 3 level. In addition to NUTS 2 level regions, we included NUTS 3 level regions from certain countries to better cover remote regi ons in the analysis (see A ppendix). 
Table 1. Means of the variables by region type (yearly averages in 1991-2010)

\begin{tabular}{lllll}
\hline Region type & $\begin{array}{l}\text { Accessibility } \\
\text { index }\end{array}$ & $\begin{array}{l}\text { Air passengers } \\
\text { (1000) }\end{array}$ & $\begin{array}{l}\text { Employment } \\
(1000)\end{array}$ & $\begin{array}{l}\text { Real GDP } \\
\text { (Mio euro ppp) }\end{array}$ \\
\hline $\begin{array}{l}\text { Peripheral } \\
\text { Intermediate }\end{array}$ & 102.7 & 1981.8 & 376.4 & 19.992 .3 \\
Core & 113.3 & 4794.8 & 703.2 & 44819.7 \\
\hline All regions & 101.5 & 78539.6 & 1154.0 & 77196.3 \\
\hline
\end{tabular}

We performed Granger causality tests between regional growth and air transportation in 86 European regions for the period from 1991-2010 and with lags one and two. The method would also have allowed the use of current values of $x$ but we discarded the contemporaneous case to be able to better identify the lead-lag relationship between the two variables. For both side variables in the analysis, we first take natural logarithms and then difference them to eliminate possible unit roots and to reach time stationarity. Consequently, we are thereby analyzing growth rates. We follow the nested procedure described above to test different causality relationships. The tests are based on Wald statistics.

\section{RESULTS}

As a first step in exploring bi-directional Granger causality between airport activity and regional development, we assess the homogeneous non-causality 
(HNC) hypothesis. The HNC hypothesis implies the non-existence of individual causality relationships. In model (1), the corresponding test is defined as follows:

(2) $H_{0}: \beta_{\mathrm{i}}(\mathrm{k})=0 \forall \mathrm{i} \in[1, \mathrm{~N}], \forall \mathrm{k} \in[1, \mathrm{p}]$

$$
\mathrm{H}_{1}: \exists(\mathrm{i}, \mathrm{k}) / \beta_{\mathrm{i}}(\mathrm{k}) \neq 0 .
$$

For testing $\mathrm{N} p$ linear restrictions in (2), the following Wald statistic is computed:

(3) $\quad F_{H N C}=\frac{\left(R S S_{2}-R S S_{1}\right) / N p}{R S S_{1} /(N T-N(1+p)-p)}$,

where $\mathrm{RSS}_{2}$ denotes the restricted sum of squared residuals obtained under $\mathrm{H}_{\circ}$ and $\mathrm{RSS}_{1}$ corresponds to the residual sum of squares of model (1). If the individual effects $a_{\mathrm{i}}$ are assumed to be fixed ${ }^{4}$, the sum of squared residuals is obtained from the maximum likelihood estimation (MLE), which in this case corresponds to the fixed effects (FE) estimator. It has been shown that the FE estimator is biased in a case in which T is small (Nickell, 1981), but the bias decreases with $\mathrm{T}$. We favor the FE estimator because the bias may not be large, and its use enables us to follow the testing procedure. Accordingly, the testing procedure can be implemented using the constrained regression technique

\footnotetext{
4The Hausman test also supported the existence of fixed effects instead of random effects.
} 
(Hood III et al, 2008; Hurlin and Venet, 2001). Interpretation of the statistic relies on the Fischer distribution with $N p$ and $(N T-N(1+p)-p)$ degrees of freedom.

To measure regional performance (y), we use two variables, GDP growth and employment growth, and we use two variables to measure air traffic $(x)$, the number of air passengers and accessibility. Table 2 presents the results from four possible combinations of the variables: air passengers and GDP; air passengers and employment; accessibility and GDP; and accessibility and employment. ${ }^{5}$

Table 2. Test results for homogeneous non-causality (HNC hypothesis)

\begin{tabular}{lllll}
\hline Direction of & \multicolumn{4}{c}{ F-statistic and its significance } \\
causality and & Air passengers Air passengers & Accessibility & Accessibility \\
lags & -GDP & - employment & -GDP & -employment \\
\hline
\end{tabular}

Causality from air traffic to regional growth

$\begin{array}{lllll}\operatorname{Lag} 1 & 1.602^{* * *} & 1.591^{* * *} & 1.947^{* * *} & 1.947^{* * * *} \\ \operatorname{Lag} 2 & 0.576 & 0.716 & 0.991 & 1.391^{* * *}\end{array}$

Causality from regional growth to air traffic

$\begin{array}{lllll}\operatorname{Lag} 1 & 0.956 & 1.206^{*} & 0.694 & 1.016 \\ \operatorname{Lag} 2 & 0.420 & 0.604 & 0.470 & 0.586\end{array}$

Note: *** Rejection of $\mathrm{H}_{\circ}$ at $1 \%$ level of significance; ** Rejection of $\mathrm{H}_{\circ}$ at $5 \%$ level of significance; Rejection of $\mathrm{H}_{0}$ at $10 \%$ level of significance.

5 In addition, despite its shortcomings, we also estimated the model with the variable for air cargo. The homogenous non-causality hypothesis was not rejected in either case. The testing procedure stopped in the first step, implying that there were no causal relationships in either direction between air traffic and regional development. This result, however, most likely reflects more about the limitations of the cargo variable than about the actual state of affairs. 
All the test statistics related to the homogenous non-causality hypothesis are statistically significant with one lag when the direction of causality is from air traffic to regional development. With two lags, however, these statistics are not significant, with the exception of the pair of variables "accessibility employment". These results allow us to reject the homogeneous non-causality hypothesis because there is statistical evidence of Granger causality from air traffic (accessibility) to regional growth for at least some regions (and possibly all).

The evidence of the opposite direction of causality - from regional development to air traffic - is only partial. The test statistics cannot be rejected even at lag one when using the combination of variables "air passengers - GDP", "accessibility GDP" or "accessibility - employment". It is, however, rejected at the $10 \%$ significance level when airport activity is measured by the number of air passengers and employment is used instead of GDP. This rejection calls for the next step in the testing procedure.

If the HNC hypothesis is rejected, the next step is to test the hypothesis of homogeneous causality $(\mathrm{HC})$. The $\mathrm{F}_{\mathrm{HC}}$ test statistic is calculated using the sum of squared residuals from the unrestricted model described above $\left(\mathrm{RSS}_{1}\right)$ and the sum of squared residuals $\left(\mathrm{RSS}_{3}\right)$ from a restricted model in which the slopeterms 
are constrained to equality for all of the panel members in the sample. Thus, the hypotheses are as follows:

(4)

$$
\begin{aligned}
& \mathrm{H}_{0}: \forall \mathrm{k} \in[1, \mathrm{p}] / \beta_{\mathrm{i}}(\mathrm{k})=\beta^{(\mathrm{k})} \forall \mathrm{i} \in[1, \mathrm{~N}] \\
& \mathrm{H}_{1}: \exists \mathrm{k} \in[1, \mathrm{p}], \exists(\mathrm{i}, \mathrm{j}) \in[1, \mathrm{~N}] / \beta_{\mathrm{i}}(\mathrm{k}) \neq \beta_{\mathrm{j}}(\mathrm{k}),
\end{aligned}
$$

and the test statistic is

(5) $\quad F_{H C}=\frac{\left(R S S_{3}-R S S_{1}\right) / p(N-1)}{R S S_{1} /(N T-N(1+p)-p)}$.

As with $\mathrm{HNC}$, if the individual effects $a_{i}$ are assumed to be fixed, the ML estimator is consistent with the FE estimator. As the results related to the use of two lags showed insignificance above in most cases, we used only lag 1 here.

The results presented in Table 3 indicate significant test statistics for all pairs of variables when the direction of causality is from air traffic to regional growth. Accordingly, we can state at this point that there are causal processes from air traffic (accessibility) to regional growth, but these processes are not uniform. The test statistic about the opposite direction of causality, where employment causes air traffic in all regions, is not rejected, implying a homogenous causal process. 
An alternative interpretation is that there are no causal processes at all. This is the result we obtain with all of the other pairs of variables.

Table 3. Test results for homogenous causality (HC hypothesis)

\begin{tabular}{lllll}
\hline Direction of & \multicolumn{4}{c}{ F-statistic and its significance } \\
causality & Air passengers Air passengers & Accessibility & Accessibility \\
& - GDP & - employment & - GDP & -employment \\
\hline
\end{tabular}

Causality from air traffic to regional growth

$\begin{array}{lllll}\text { Lag } 1 & 1.646^{* * *} & 1.521^{* * *} & 2.018^{* * *} & 1.950^{* * *}\end{array}$

Causality from regional growth to air traffic

$\operatorname{Lag} 1 \quad-\quad 0.925$

Note: *** Rejection of $\mathrm{H}_{0}$ at $1 \%$ level of significance; ** Rejection of $\mathrm{H}_{0}$ at $5 \%$ level of significance;

Rejection of $\mathrm{H}_{0}$ at $10 \%$ level of significance.

The results thus far indicate that air traffic, or accessibility in general, Grangercauses regional growth in some regions, but not in all regions. The datagenerating process is non-homogeneous, and homogeneous causality relationships cannot be obtained. It may, however, still be possible that causality relationships continue to exist for one or more regions. There is a need for further analysis and testing for the heterogeneous non-causality hypotheses. As the number of regions is high at 86 , we did not test the contribution of each individual region to the existence of causality; instead, we categorized the regions into three groups according to their peripherality. The categorization is especially important because we wish to analyze the significance of remote airports to their regions. 
The third step is to test the heterogeneous non-causality hypothesis (HENC). The F HeNC statistic is calculated using RSS $_{1}$, obtained above, in addition to the sum of squared residuals $\left(\mathrm{RSS}_{4}\right)$ from a model in which the slope coefficients for the panel members in the subgroup in question are constrained to zero.

The test examines the joint hypothesis that there are no causality relationships for a subgroup of regions. In this case, the Wald statistic is as follows:

(6) $\quad F_{H E N C}=\frac{\left(R S S_{4}-R S S_{1}\right) /(n n c p)}{R S S_{1} /(N T-N(1+p)-n c p)}$,

where $\mathrm{RSS}_{4}$ corresponds to the realization of the residual sum of squares obtained in model (1) when one imposes the nullity of the $k$ coefficients associated with the variable $x_{i, t-k}$ on the $n_{n c}$ regions of the subgroup. The number of regions not belonging to the subgroup is $n_{c}$ (for which $\beta$ is not constrained to $0)$.

Interestingly, the results shown in Table 4 suggest that peripherality indeed matters. The more peripheral a region is, the more important it is to its development to have efficient air connections. This conclusion is most evident with the pair of variables "air passengers - GDP". For peripheral regions, the 
statistical test results are significant with all combinations of variables; for the other regions, the results vary somewhat, depending on the variables.

Table 4. Test results for heterogeneous causality (HENC hypothesis, lag 1)

\begin{tabular}{|c|c|c|c|c|}
\hline \multirow{3}{*}{$\begin{array}{l}\text { Direction of } \\
\text { causality and } \\
\text { region type }\end{array}$} & \multicolumn{4}{|c|}{ F-statistic and its significance } \\
\hline & Air pass & s Air passengers & Accessibility & Accessibility \\
\hline & - GDP & - employment & - GDP & -employment \\
\hline \multicolumn{5}{|c|}{ Causality from air traffic to regional growth } \\
\hline Peripheral regions & $2.527^{* 1 *}$ & $3.533 * 1 *$ & $2.952 * 1 *$ & $4.685^{* 11 k}$ \\
\hline Intermediate regions & $1.374 *$ & 0.760 & 1.152 & 0.618 \\
\hline Core regions & 0.873 & 0.393 & $1.607^{*}$ & 0.385 \\
\hline
\end{tabular}

Note: *** Rejection of $\mathrm{H}_{0}$ at $1 \%$ level of significance; ** Rejection of $\mathrm{H}_{0}$ at $5 \%$ level of significance; Rejection of $\mathrm{H}_{0}$ at $10 \%$ level of significance.

\section{Conclusions}

This study focuses on the importance of air transportation in various European regions. We are particularly interested in the relationship between air transportation and regional growth in peripheral regions. This focus is different compared to that of most prior studies, which have concentrated on hub airports and the development of metropolitan areas. In peripheral regions, air traffic may decrease the negative effects of long distances. Easy accessibility together with production costs advantages attracts firms, investments and other economic activity to the region and stimulates employment and production at established firms. Earlier studies and surveys clearly indicate that access to air transportation 
has an extremely important effect on the locational decisions of many businesses. A well-developed transportation infrastructure is a facilitator that encourages the economic potential of a region to be realized.

The Granger non-causality method in a panel framework that allows possible heterogeneity between regions offers a new approach to the analysis of the relationship between air traffic and economic development. Our results present evidence of causal processes in these relationships and suggest that air transportation is more than a facilitator in remote regions. In these regions, in addition to regional growth causing airport activity, air activity appears to boost regional development. Supply-side effects are, thus, important for distant regions. In core regions, only the reverse is true: that is, airport activity does not cause regional growth, but regional growth causes airport activity. ${ }^{6}$ The regions analyzed were from Western Europe. Would the same result be true, or indeed be more pronounced, in Eastern European or the most recent EU accession states, is a question that would need further investigation.

\footnotetext{
6 It should be noted that while Granger causality represents progress toward uncovering true causal processes, it is indicative rather than confirmatory. While airport activity may appear to cause economic development because lagged airport activity values carry explanatory power, the apparent causation may, in fact, be due to omitted variables that move in tandem with airport activity but are not picked up in lagged economic development values. Moreover, lagged airport values may sometimes be generated in response to anticipated future economic development values; that is, airports are originally built for regions that have the most potential for economic success.
} 
Given these results, the message for regional policy makers is that there are good reasons to defend local airlines because they are important to the development of remote regions. The traditional challenge for many small airports in remote areas is that they are not financially viable. This has led to financial support being provided to airports and airport companies by central or local authorities 7 . Although subsidies often distort competition and waste money, our results suggest that there indeed might be a case for subsidizing local airports in remote regions if the result is increased regional growth and welfare.

\section{Acknowledgements}

This paper is a part of ADES project "Airports as economic drivers of economic success in peripheral regions", conducted under Priority 2 of the ESPON 2013 Programme. The paper has been written with the support of the Academy of Finland (research project 127049). Special thanks are due to Dr Urs Muller.

\section{References}

Alkaabi K A, Debbage K G, 2007, "Air passenger demand and skilled labor markets by US metropolitan area" Journal of Airport M anagement 13121-130

Baltagi B H, 2005 Econometric analysis of panel data (Wiley, N ew York)

Bråthen S, 2011, “Air transport services in remote regions", Discussion paper No. 2011-13, International Transport Forum

\footnotetext{
${ }^{7}$ EU legislation (Regulation (EC) No 1008/ 2008) al lows Member States to impose a public service obligation (PSO) in order to provide scheduled air services on routes which are vital for the economic development of the region they serve. This may involve financial compensation provided by public sector. N orway and France have the largest number of PSO routes (Bråthen, 2011). Regional authorities may also consider air transport services particularly important (without PSO) for the development of their region, and decide to support the airline operator financially (e.g. in Finland).
} 
Brueckner J K, 2003, "Airline traffic and urban economic development" U rban Studies 40(8) 1455-1469

Button K, Doh S, Yuan J, 2010, "The role of small airports in economic development" Journal of Airport M anagement 4(2) 125-136

Button K, Lall S, Stough R, Trice M, 1999, "High-technology employment and hub airports" Journal of A ir Transport M anagement 553-59

Button K, Taylor S, 2000, "International air transportation and economic development" Journal of A ir Transport M anagement 6 209-222

Debbage K, 1999, "Air transportation and urban-economic restructuring: competitive advantage in the US Carolinas" Journal of Air Transport $M$ anagement 5211-221

Debbage K G, Delk D, 2001, The geography of air passenger volume and local employment patterns by US metropolitan core area: 1973-1996 Journal of Air Transport $M$ anagement $7159-167$

Erdil E, Yetkiner I H, 2009, "The Granger-causality betwen health care expenditure and output: a panel data approach" A pplied E conomics 41511-518 ESPON, 2012, "ADES. Airports as drivers of economic success in peripheral regions. Targeted Analysis 2013/ 2/ 17" Interim Report (Draft)

Freestone R, 2009, "Planning, sustainability and airport-led urban development" International Planning Studies $\mathbf{1 4}$ 161-176

Goetz A R, 1992, "Air passenger transportation and growth in the U.S. urban System 1950-1987" G rowth and Change 23218-242

Granger C W J, 1969, "Investigating causal relations by econometric models and cross-spectral methods" Econometrica 37 424-438

Green R, 2007, "Airports and economic development" Real Estate Economics 35 91-112

Holt-Eakin D, Newey W, Rosen H, 1988, “Estimating vector autoregressions with panel data" Econometrica 56 1371-1395

Hood III M V, Kidd Q, Morris I, 2008, "Two sides of the same coin? Employing Granger causality tests in a time series cross-section framework" Political A nalysis 16 324-344

H siao C, 1986 A nalysis of panel data (Cambridge University Press, Cambridge).

Hurlin C, Venet B, 2001, “Granger causality tests in panel data models with fixed coefficients", Mimeo, University of Paris IX

Hurlin C, Venet B, 2005, "Testing for Granger causality in hetereogenous panel data models" (English title) Revue Economique 56 1-11 
Ivy R L, Malecki E J, 1995, "Changes in air service connectivity and employment" Environment and Planning A 27 165-179

Krugman P, 1991, "Increasing returns and economic geography" Journal of Political Economy 99 483-499

Markusen A R, Hall P, Glasmeier A, 1986 High-tech A merica: the what, how, where, and why of the sunrise industries (Allen and Unwin, Boston)

Martin P, Rogers A C, 1995, "Industrial location and public infrastructure" Journal of International Economics 39335-351

Ministry of Transport and Communication Finland, 2010, "Kotimaan lentoliikenteen tilanne erityisesti Porin, Seinäjoen ja Jyväskylän lentokentillä", Selvitys 29/2010, Helsinki

N doh N N, Caves R E, 1995, "Investigating the impact of air-service supply on local demand a causal analysis" Environment and Planning A 27 489-503

Nickell S, 1981, "Biases in dynamic models with fixed effects" Econometrica 49 1399-1416

Peck F W, 1996, "Regional development and the production of space: the role of infrastructure in the attraction of new inward investment" Environment and Planning A 28327-339

Tervo H, 2009, "Centres and peripheries in Finland: Granger causality tests using panel data" Spatial Economic A nalysis 4377-390

Venables A, Gasiorek M, 1998, "The welfare impact of transport improvements in the presence of market failure", Report to the Standing Advisory Committee on Trunk Assessment, UK

Vickerman R, 1996, "Location, accessibility and regional development: the appraisal of trans-European networks" Transport Policy 2225-234

Vickerman R, Spiekermann K, Wegener M, 1999, “Accessibility and economic development in Europe" Regional Studies 331-15

Yao S, Yang X, 2008, "Airport development and regional economic growth in China", Research Paper 07, University of Nottingham 
A ppendix. Regions in the data

\begin{tabular}{|c|c|c|c|}
\hline Country & NUTS & Name of the region & Region type* \\
\hline \multirow[t]{3}{*}{ Austria } & AT12 & Niederösterreich & $\bar{i}$ \\
\hline & AT13 & Wien & C \\
\hline & AT32 & Salzburg & $\mathrm{i}$ \\
\hline \multirow[t]{3}{*}{ Switzerland } & $\mathrm{CHO1}$ & Bassin Lémanique & c \\
\hline & $\mathrm{CHO3}$ & Basel & c \\
\hline & $\mathrm{CHO}$ & Zurich & c \\
\hline \multirow[t]{13}{*}{ Germany } & DE11 & Regierungsbezirk Stuttgart & c \\
\hline & DE21 & Regierungsbezirk Oberbayern & c \\
\hline & DE25 & Regierungsbezirk Mittelfranken & c \\
\hline & DE30 & Regierungsbezirk Berlin & c \\
\hline & DE42 & Brandenburg- Südwest & $\mathrm{i}$ \\
\hline & DE50 & Regieringsbezirk Bremen & $\mathrm{i}$ \\
\hline & DE60 & Regierungsbezirk Hamburg & C \\
\hline & DE71 & Regierungsbezirk Darmstadt & c \\
\hline & DE92 & Hannover & c \\
\hline & DE94 & Weser-Ems & C \\
\hline & DEA 1 & Regierungsbezirk Düsseldorf & c \\
\hline & DEA 2 & Regierungsbezirk Köln & c \\
\hline & DEA 3 & Regierungsbezirk Münster & c \\
\hline Denmark & DK01 & Hovedstaden & $\mathrm{i}$ \\
\hline \multirow[t]{22}{*}{ Spain } & ES111 & A Coruña & $\mathrm{p}$ \\
\hline & ES114 & Pontevedra & $p$ \\
\hline & ES12 & Principado de Asturias & $\mathrm{p}$ \\
\hline & ES13 & Cantabria & $\mathrm{p}$ \\
\hline & ES211 & Álava & $p$ \\
\hline & ES212 & Guipúzcoa & $\mathrm{p}$ \\
\hline & ES213 & Vizcaya & $p$ \\
\hline & ES243 & Zaragoza & $p$ \\
\hline & ES415 & Salamanca & $p$ \\
\hline & ES418 & Valladolid & $\mathrm{p}$ \\
\hline & ES431 & Badajoz & $\mathrm{p}$ \\
\hline & ES512 & Girona & $p$ \\
\hline & ES514 & Tarragona & $\mathrm{p}$ \\
\hline & ES521 & Alicante & $p$ \\
\hline & ES523 & Valencia & $p$ \\
\hline & ES611 & Almería & $\mathrm{p}$ \\
\hline & ES613 & Córdoba & $\mathrm{p}$ \\
\hline & ES614 & Granada & $p$ \\
\hline & ES617 & Málaga & $p$ \\
\hline & ES618 & Sevilla & $\mathrm{p}$ \\
\hline & ES62 & Región de Murcia & $p$ \\
\hline & ES64 & Ciudad A utónoma de Melilla & p \\
\hline
\end{tabular}




\begin{tabular}{|c|c|c|c|}
\hline \multirow[t]{12}{*}{ France } & FR22 & Picardie & c \\
\hline & FR24 & Centre & i \\
\hline & FR3 & Nord-Pas-de-Calais & c \\
\hline & FR421 & Bas-Rhin & C \\
\hline & FR422 & Haut-Rhin & C \\
\hline & FR61 & Aquitane & i \\
\hline & FR717 & Savoie & i \\
\hline & FR72 & Auvergne & i \\
\hline & FR81 & Languedoc-Roussillon & i \\
\hline & FR823 & Alpes-Maritimes & i \\
\hline & FR824 & Bouches-du-Rhône & i \\
\hline & RF825 & Var & $\mathrm{p}$ \\
\hline \multirow[t]{2}{*}{ Ireland } & IR21 & Dublin & i \\
\hline & IR23 & Mid-West I reland & $\mathrm{p}$ \\
\hline \multirow[t]{7}{*}{ Italy } & IT111 & Torino & i \\
\hline & IT133 & Genova & i \\
\hline & IT201 & Varese & C \\
\hline & IT325 & Venezia & i \\
\hline & IT333 & Gorizia & i \\
\hline & ITE4 & Lazio & i \\
\hline & ITF3 & Campania & i \\
\hline Luxembourg & LU & Luxembourg & c \\
\hline \multirow[t]{2}{*}{ The Netherlands } & NL32 & Noord-Holland & c \\
\hline & NL42 & Limburg & c \\
\hline \multirow[t]{2}{*}{ Norway } & NO033 & Vestfold & $\mathrm{p}$ \\
\hline & NO043 & Rogaland & $\mathrm{p}$ \\
\hline \multirow[t]{3}{*}{ Portugal } & PT11 & Portugal N orte & $p$ \\
\hline & PT15 & Algarve & $p$ \\
\hline & PT17 & Lisboa & $\mathrm{p}$ \\
\hline \multirow[t]{15}{*}{ United Kingdom } & UKC1 & Tees Valley and Durham & i \\
\hline & UKC2 & Northumberland and Tyne and Wear & i \\
\hline & UKD3 & Greater Manchester & c \\
\hline & UKE1 & East Riding and North Lincolnshire & i \\
\hline & UKE4 & West Yorkshire & i \\
\hline & UKF1 & Derbyshire and Nottinghamshire & i \\
\hline & UKF2 & Leicestershire, Rutland and Northamptonshire & c \\
\hline & UKG3 & West Midlands & C \\
\hline & UKH2 & Bedfordshire and Hertfordshire & C \\
\hline & UKII & Inner London & C \\
\hline & UKI2 & Outer London & C \\
\hline & UKK1 & Gloucestershire, Wiltshire and North Somerset & i \\
\hline & UKL2 & East Wales & i \\
\hline & UKM 1 & A berdeen Region & i \\
\hline & UKM2 & Eastern Scotland & i \\
\hline
\end{tabular}

*p = peripheral; $\mathrm{i}=$ intermediate; $\mathrm{c}=$ core 